\title{
Rain-derived particles and CDOM distribution along the East Coast of New Caledonia
}

\author{
Cécile Dupouy ${ }^{{ }^{*} a}$, Guillaume Wattelez ${ }^{\mathrm{a}}$, Jérôme Lefèvre ${ }^{* b}$, Farid Juillot ${ }^{{ }^{*} \mathrm{c}}$, Rémi Andréoli ${ }^{\mathrm{d}}$, Didier \\ Lille $^{\mathrm{d}}$, Hiroshi Murakami ${ }^{\mathrm{e}}$, Rudiger Röttgers ${ }^{\mathrm{f}}$, Robert Frouin ${ }^{\mathrm{g}}$ \\ ${ }^{a}$ IRD, MIO, Marseille, France; ${ }^{b}$ IRD, LEGOS, Toulouse, France; \\ 'IRD, IMPMC, UMR 7590, CNRS, University Pierre et Marie Curie, Paris, France; ${ }^{\mathrm{d}}$ JBluecham \\ SAS, Nouméa; ${ }^{\mathrm{e} J A X A}$ EORC,Tsukuba, Japan; \\ ${ }^{\mathrm{f}} \mathrm{HZG}$, Geesthacht, Germany; ${ }^{\mathrm{g}} \mathrm{SIO} / \mathrm{UCSD}$, La Jolla, USA
}

* IRD Nouméa, New Caledonia

\begin{abstract}
Shortly after strong rains or tropical storms, chlorophyll-a concentration (Chla), turbidity, and colored dissolved organic matter (CDOM) in the lagoon of New Caledonia may be tripled. This effect is visible as far as $50 \mathrm{~km}$ offshore. The Eastern Coast of New Caledonia is more impacted than the Western Coast because of its geomorphological structure. Higher frequency and intensity of the rains, and the dominance of highly erosive lateritic formations resulted from deep weathering of ultramafic rocks. At the deeper parts of the lagoon (> $20 \mathrm{~m}$ ), increases of Chla, turbidity, and CDOM absorption can be detected by satellite imagery with their plumes extending off shore as a result of wind-driven circulation in the lagoon. Such -increases agree with the oceanographic measurements of Chla, absorption, backscattering, turbidity and CDOM during extensive cruises. Satellite and in situ measurements allow tracing of particulates and dissolved matter in lagoon waters and up to the coral barrier reefs. The largest particles settle at a short distance from the coast influencing the sediments not far from the river outflows. Fine particles $(<10 \mu \mathrm{m})$, colloids and/or CDOM are exported to reefs where they can be beneficial through protection from high UV illumination (colloids) and feeding of the corals (CDOM). Phytoplankton and associated detritus, when not dominated by toxic filamentous cyanobacteria, can also feed coral reefs. Finally, the export of fine particles associated with colloids and/or CDOM can also contribute to the distribution of trace metals to the barrier reefs of the East Coast and offshore. The question whether this input of trace metals has an overall positive or negative effect on the coral reefs is still under debate.
\end{abstract}

Keywords: Minerals, Phytoplankton, CDOM, FDOM, Ocean color, Reflectance, New Caledonia, Tropical Pacific Ocean, Lagoons

\section{INTRODUCTION}

The distribution in time and space of biogeochemical parameters such as chlorophyll-a concentration (Chla), turbidity, and colored dissolved organic matter (CDOM) can be retrieved by satellite. For this, the variability of bio-optical parameters as supplied by NASA in standard satellite products, can be analyzed to test the relevance of standard algorithms in regional approaches to analyze spatial and temporal changes. The NASA products are obtained according to correlations in mixed type of waters from a global data basis (SeaBaSS). Chla is a proxy of phytoplankton concentration and gives information about the water quality and health of an environment, i.e., its capacity to allow the phytoplankton to develop (size $>0.7 \mu \mathrm{m}$ ). Turbidity is an indicator of suspended particles abundance (size $>0.4 \mu \mathrm{m}$ ) while CDOM is an indicator of organic molecules $(<0.2$ $\mu \mathrm{m})$. Recent studies based on in situ data [1] have shown that NASA algorithms overestimate Chla in shallow 
waters of lagoons and underestimate it offshore ([2, 3, 4]). Thus Chla can be estimated by regional algorithms (for water depths $>20$ meters) [5, 6] and other methods for shallow waters $(<20 \mathrm{~m})$ [7]. Turbidity can be estimated through various parameterizations and was measured and estimated along the Eastern coast of New Caledonia [8] or [10]. Backscattering coefficient and absorption coefficients can be inverted from marine reflectance as for example, backscattering can be retrieved as in [9] and CDOM calculated from the $\mathrm{Kd}_{490}$ parameter available from NASA, using [11]. All these bio-optical parameters were measured along the Eastern Coast of New Caledonia during cruises in order to estimate uncertainties of global algorithms.

The "health" of the New Caledonia lagoon (South Pacific) is of prime importance to local island populations for food picking, local fisheries, water renewal and transport, recreation activities, and was classified as the a UNESCO Heritage site in 2008. Minerogenic particle, phytoplankton, and CDOM concentration result from exchanges with the surrounding sea and inputs from river catchments, which can modify the water state from oligotrophic to mesotrophic (yearly average Chla and turbidity of 0.07-0.5 $\mathrm{mg} \cdot \mathrm{m}^{-3}$ and $0.20-16 \mathrm{~g} \cdot \mathrm{m}^{-3}$, respectively). The bathymetry of the lagoon is heterogeneous due to the complex geomorphology and variety of bottom types. Shortly after strong rain events or tropical storms, the concentrations of Chla, turbidity, and CDOM in the lagoon of New Caledonia can be three times higher [10, 12]. The Eastern Coast is more impacted than the Western Coast because of its geomorphological structure (some mountains descending abruptly to the deep (> 60m) lagoon, higher frequency and intensity of rains and the dominance of highly erosive lateritic formations resulting from deep weathering of ultramafic rocks. High runoffs due to rain carrying abundant CDOM and particle loads may greatly impact the functioning of the lagoon ecosystems [10] while rivers and sewage effluents may induce localized negative impacts as a drastic reduction of transparency, which extents are totally unknown. Our objective was to identify the amounts of CDOM and suspended matter transported along the basin-slope-lagoon continuum at the Eastern side of New Caledonia from MODIS archived data available for the years 2002-2010 and after a validation by local in situ data.

\section{DATA AND METHODS}

Our validation data set from the Eastern Coast was collected during three CALIOPE cruises [12] (Figure 1). The first cruise (CALIOPE 1 in October 2011), was conducted during a typical dry and warm period, the second one (CALIOPE 2 in March 2014) during a moderate rain and strong wind period [8], while the third cruise (CALIOPE 3 in March 2016) took place during a strong rain event with low winds. The data set also included measurements from a year-long survey along a transect of 3 stations off the mining village of Thio located in the middle of the Eastern Coast [10] with $\mathrm{CH} 1, \mathrm{CH} 2$, and $\mathrm{CH} 3$ corresponding to the first stations of a CALIOPE transect. Among the three stations of the Thio transect, only "CH3" situated in the middle of lagoon at $>20 \mathrm{~m}$ water depth was used for the coincidence retrieval with the MODIS data, while the more coastal stations "CH1" and "CH2" often masked on satellite pictures as optically shallow were not used for comparisons. For the analysis of the biogeochemical parameters variability from the MODIS archive in the Eastern lagoon, we selected five stations at equal distance from $\mathrm{CH} 3$, with 2 other stations inside the lagoon and 2 stations outside (off the barrier reef, at $>200 \mathrm{~m}$ water depths).

Among optical properties, backscattering coefficients, $b_{\mathrm{b}}(\lambda)$, were measured with a Hydroscat-6 profiler (H6: HobiLabs; wavebands centered at 442, 488, 510, 550, 620 and $670 \mathrm{~nm}$; with a bandwidth of $10 \mathrm{~nm}$ for 442 to $550 \mathrm{~nm}$ bands, and $20 \mathrm{~nm}$ for the 620 and $670 \mathrm{~nm}$ bands).The particulate backscattering coefficient, $b_{\mathrm{bp}}(\lambda)$, was calculated by subtracting from $b \mathrm{~b}(\lambda)$ the theoretical "pure water spectrum, bbw (determined by $b_{\mathrm{bw}}(\lambda)=$ $\left.0.5 b_{\mathrm{w}}(\lambda)\right)$, as in $[5,6]$. The spectral absorption coefficient of CDOM ( $a_{\mathrm{g}}$, g for Gelbstoff) was measured using the Point-Source Integrating-Cavity Absorption Meter, PSICAM, instrument and $0.22-\mu \mathrm{m}$ filtered seawater samples as in [13] or by using a liquid core waveguide system (WPI; $200 \mathrm{~mm}$ path length) as in [10]. Chla was measured by fluorometry (sum of chlorophyll a and pheopigments in mg. $\mathrm{m}^{-3}$ ). Turbidity in FTU was obtained from an Seabird ECOFLNTU sensor calibrated with values of gravimetrically determined mass 
concentrations of suspended particulate matter (SPM) [5]. Hyperspectral remote sensing reflectance $\left(\mathrm{R}_{\mathrm{rs}}\right)$ spectra were derived from a TriOS system measuring $L_{\mathrm{u}}(0-, \lambda)\left(\mathrm{FOV}=7^{\circ}\right)$ and $E_{\mathrm{d}}(0+, \lambda)$ for $\lambda=320 \mathrm{~nm}$ to 950 $\mathrm{nm}$ with $\Delta \lambda \sim 10 \mathrm{~nm}$ (sampled by every $3.3 \mathrm{~nm}$ ) as in [2].

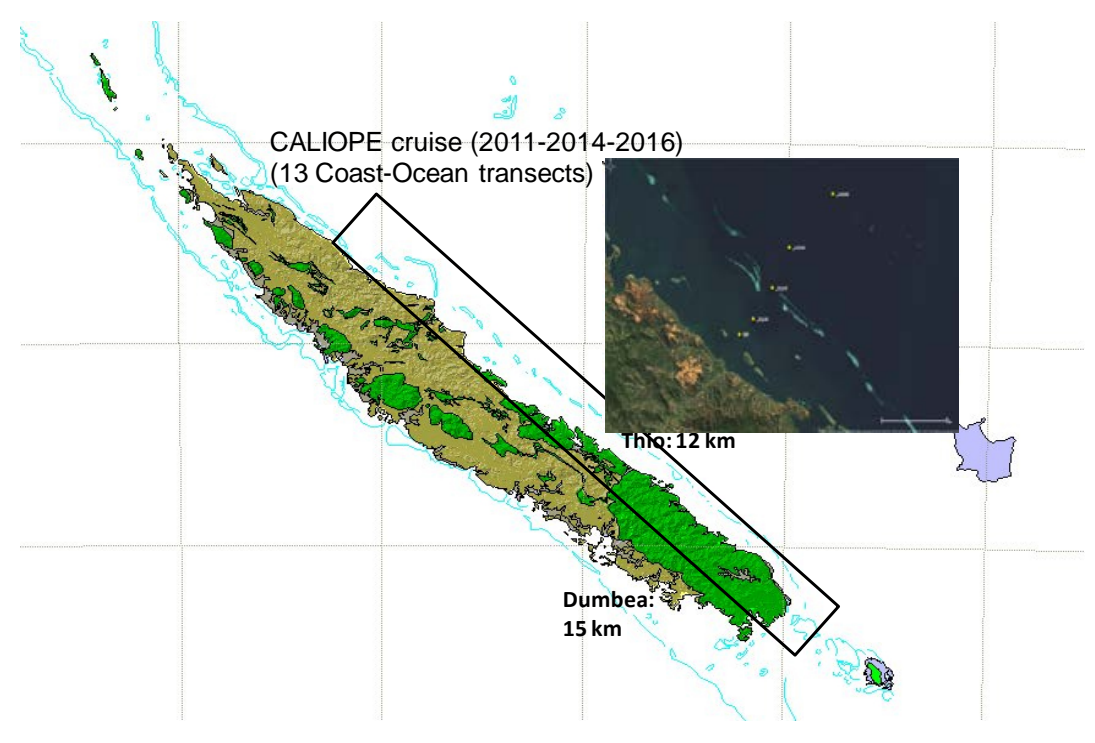

Figure 1. Sampling areas around New Caledonia and an associated Sentinel 3 image. The transect off Thio is indicated in the image, with $\mathrm{CH} 3$ as the most coastal station for which data are extracted from MODIS imagery. CH3 (166.256 E ; 21.573 S); lagoon1 (166.277 E ; 21.557 S); lagoon2 (166.304 E ; 21.524 S); ocean1 (166.330 E ; 21.481 S); ocean2 (166.394 E ; 21.424 S).

MODIS imagery of New Caledonia waters was processed for the years 2002-2010 [14]. Products are all MODIS bands marine remote sensing reflectances, corrected from the atmosphere, $R_{\mathrm{r}}$, at $1 \mathrm{~km}$ resolution were calculated at $250 \mathrm{~m}$ resolution using NASA procedures in Seadas. From these $R_{\mathrm{rs}}$ spectra, values of Chla were inverted using the OC3 algorithm developed by the NASA in Seadas and generally applicable to oceanic waters, and from the AlgoNC, specially designed for waters of the New Caledonian lagoon [4]. Turbidity was calculated according to [5].

The backscattering coefficient at $550 \mathrm{~nm}, b_{\mathrm{bp}}(550)$, was estimated from $K_{\mathrm{d}}(490)$ values by the empirical equation of [9] as in Eq. (1)

$$
\mathrm{b}_{\mathrm{bp}}(550)=-0.0001568+0.0304 \times\left(\mathrm{Kd}_{(490)}\right)^{1.109} ; \mathrm{R}^{2}=0.790
$$

The CDOM absorption coefficient at $412 \mathrm{~nm}, a_{\mathrm{g}}(412)$, was determined by the empirical equation of [11] as in Eq. (2):

$$
\mathrm{a}_{\mathrm{g}}(412)=10^{[0.548 \log 10(\mathrm{X}) 2+1.1939 \log 10(\mathrm{X})+0.0689]}
$$

with $\mathrm{X}=\left(K_{\mathrm{d}}(412)-K_{\mathrm{w}}(412)\right)-\left(K_{\mathrm{d}}(550)-K_{\mathrm{w}}(550)\right)-(\Delta \mathrm{p}(412)-\Delta \mathrm{p}(550))$, where $K_{\mathrm{w}}$ is the attenuation coefficient of pure water, and $\Delta \mathrm{p}(412)$ and $\Delta \mathrm{p}(550)$ the residual terms accounting for the scattering and absorption of suspended marine particles on the $K_{\mathrm{d}}(412)$ values which can be parameterized [11]. 
A MODIS-derived average annual cycle was calculated for each parameter. Obviously bad data were sorted out to avoid an analysis of too strongly interpolated or extrapolated data. We analyzed different series: $1^{\circ}$ the "raw" series, $2^{\circ}$ the centered series to avoid having a factor "strong concentration " on certain particular pixels, $3^{\circ}$ typical series, and $4^{\circ}$ centered typical series. The behavior of a series on a pixel from some values available on 10 years was averaged for every studied pixel (station) by using a specific filter. We calculated the monthly averages for every pixel from the complete series by removing the monthly outliers as follows:

1. Calculation of the interquartile gap, EI: where q3 is the value of the first quartile and q1 is the value of the third quartile: $E I=q_{3}-q_{1}$

2. Remove all values higher than $q_{3}+3 \times E I$

Then, we interpolated twelve values by means of cubic splines to have a value for each day. Every pixel is thus associated in the average annual cycle, that is a "smoothed" series with a "normal" value for every day. The evaluation was performed by comparing the in situ 2011-2016 database withthe values of MODIS from 2002 to 2010.

\section{RESULTS}

\subsection{Influence of heavy rains in March 2016 (CALIOPE 03)}

After period of heavy rains and low winds, as obtained during CALIOPE 03, Chl $a$ and turbidity were enhanced by a factor of 4 ([10] (Fig 2 a,b) reaching values for Chla $>0.5 \mathrm{mg} \cdot \mathrm{m}^{-3}$ and turbidity $>0.5$ FTU.

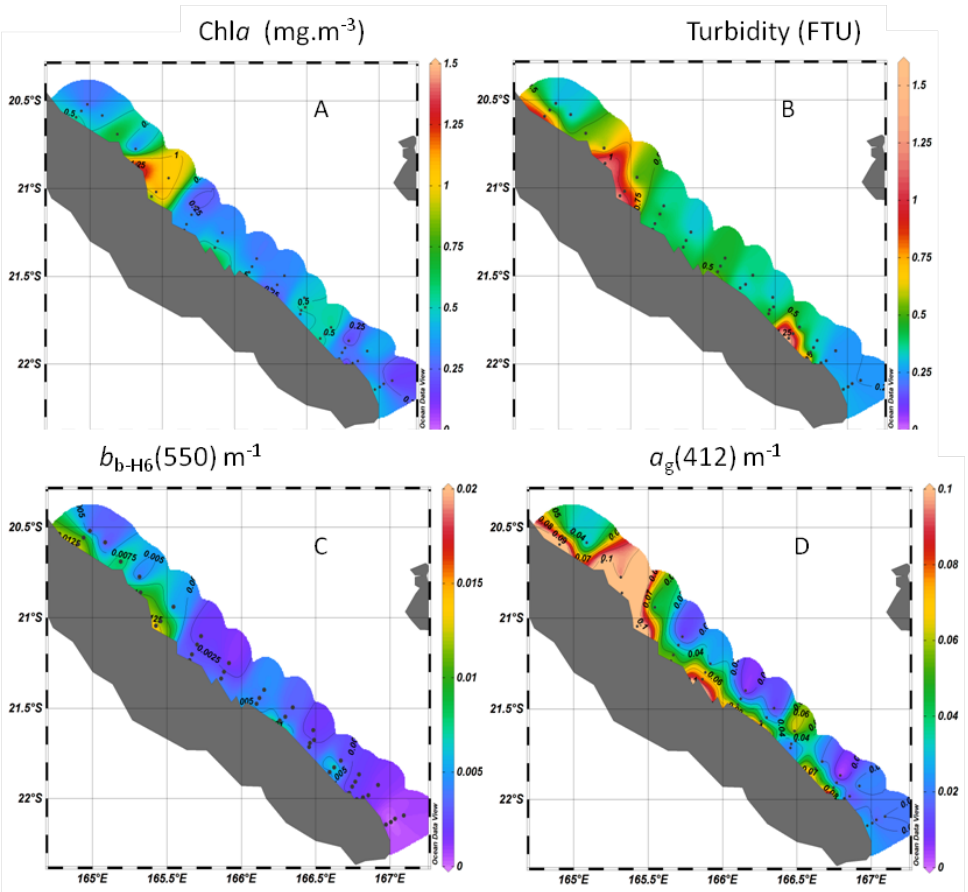

Figure 2 abcd. CALIOPE 3 biogeochemical parameters. Maps of Chla $\left(\mathrm{mg} \cdot \mathrm{m}^{-3}\right)$, Turbidity (FTU), $b_{b-\mathrm{H} 6} 550 \mathrm{~nm}$ $\left(\mathrm{m}^{-1}\right)$, and $a_{g} 412\left(\mathrm{~m}^{-1}\right)$ maps from CALIOPE 03 data (15 to 22 March 2016). 
The impact of heavy rains is visible on the values of the optical parameters like $b_{\mathrm{bp}}(550)\left(>0.01 \mathrm{~m}^{-1}\right)$ and $a_{\mathrm{g}}(412)\left(>0.06 \mathrm{~m}^{-1}\right)$ (Fig. 2 c,d). These optical parameters show similar distributions to Chla and turbidity with the most striking effect of freshwater runoffs in the Northern part of the East Coast $\left(21^{\circ} \mathrm{S}\right.$, Ponerihouen) and the Southern center (22.2 ${ }^{\circ} \mathrm{S}$, Kouakoué).

This contrasts with results during the dry period, such as that obtained during CALIOPE 01, where higher concentrations of all examined parameters are restricted to a narrow coastal band (only observed at the $1^{\text {st }}$ station of each cross-lagoon transect [15]) with a limited range of Chla, turbidity, $b_{\mathrm{bp}}(550), a_{\mathrm{g}}(412)$ of [0-0.92 mg.m $\mathrm{m}^{-3}, 0-0.2 \mathrm{NTU}, 0-0.014 \mathrm{~m}^{-1}, 0-0.06 \mathrm{~m}^{-1}$. After strong winds without rain as obtained during CALIOPE 02 (see [8]), turbidity and Chla increased at different parts along the Eastern Coast (mostly in the middle part of the island).

\subsection{Comparisons between in situ and MODIS data}

A comparison of minima and maxima of the in situ data collected during the three campaigns CALIOPE (1 - 3) and of satellite estimations from the MODIS archive 2002-2010 is shown in Table 1 for [Chla], turbidity, $a_{\mathrm{g}}(412), b_{\mathrm{bp}}(550)$ and $R_{\mathrm{rs}}(412), R_{\mathrm{rs}}(443)$ and $R_{\mathrm{rs}}(550)$, respectively.

Table 1. Comparison of minimum and maximum values of in situ and satellite measurements for various biogeochemical and optical parameters at Thio (data base 2011-2016, MODIS archive from 2002 to 2010).

\begin{tabular}{|l|ll|ll|}
\cline { 2 - 5 } \multicolumn{1}{c|}{} & \multicolumn{2}{c|}{ In situ } & \multicolumn{2}{c|}{ MODIS Satellite estimate } \\
\multicolumn{1}{c|}{$\min$} & $\max$ & $\min$ & $\max$ \\
\hline Chla (mg.m $\left.{ }^{-3}\right)$ & 0.089 & 0.891 & 0.0103 & 1.556 \\
Turbidity (NTU) & 0.117 & 1.094 & 0.0510 & 1.268 \\
$\mathrm{a}_{\mathrm{g}}(412)\left(\mathrm{m}^{-1}\right)$ & 0.0083 & 0.061 & 0.0058 & 1.513 \\
$\mathrm{~b}_{\mathrm{bp}} 550\left(\mathrm{~m}^{-1}\right)$ & 0.000089 & 0.0185 & 0.0000 & 0.0139 \\
$\mathrm{R}_{\mathrm{rs}} 412\left(\mathrm{Sr}^{-1}\right)$ & 0.0025 & 0.0102 & 0.0000 & 0.0220 \\
$\mathrm{R}_{\mathrm{rs}} 443\left(\mathrm{Sr}^{-1}\right)$ & 0.0032 & 0.0088 & 0.0000 & 0.0155 \\
$\mathrm{R}_{\mathrm{rs}} 550\left(\mathrm{Sr}^{-1}\right)$ & 0.0015 & 0.0089 & 0.0000 & 0.0070 \\
\hline
\end{tabular}

The order of magnitude of minima and maxima during all 3 cruises (2011-2016) is the same as the one calculated from MODIS reflectance (2002-2010). It is thus logical to expect that the estimates by satellites are relatively reliable. The only difference is that MODIS Rrs minimum are less than 1 10-4 which may indicate atmospheric corrections uncertainty.

\subsection{Average annual cycle for optical parameters from MODIS at the Thio site}

The average annual cycle retrieved from satellite data is shown in Figures 3-5 for all parameters and for the five stations off the village Thio during the years 2002 - 2010. We notice a strong difference between the lagoon and ocean stations indicative of a strong gradient from the coast to offshore waters. Pixels closer to the coast show higher Chla, turbidity, $a_{\mathrm{g}}(412), b_{\mathrm{bp}}(550)$ (Figure 3 and 4 ). Inversely, the $R_{\mathrm{rs}}(412)$ is lower and $R_{\mathrm{rs}}(550)$ is high (not shown), which is coherent with the observations made during CALIOPE cruises [8, 10, 15]. Generally, higher turbidity is explained by inputs of particles linked to precipitation [15]. On the other hand, all parameters are at their minimum and little variable for oceanic pixels. 


\section{Chla (off Thio, Eastern Coast of New Caledonia)}

The lagoon - ocean gradients of concentration are evident between the lagoon station (CH3, lagoon 1 and 2) and oceanic stations outside the barrier reef. We observed contrasting ranges of Chla between coastal values (from 0.4 to $0.7 \mathrm{mg} \cdot \mathrm{m}^{-3}$ ) and oceanic values (from 0.25 to $0.3 \mathrm{mg} \cdot \mathrm{m}^{-3}$ ). The variation in the average annual cycle differ when retrieved using the OC3 algorithm or using the Algo-NC (indeed, the OC3 algorithm overestimates Chla in the lagoon while AlgoNC gives higher values in the oceanic parts as already observed in [4]. The seasonal variation offshore mimics the one observed inside the lagoon though with a lower amplitude. The two peaks indicate a chlorophyll increase associated to nutrient enrichment processes linked to rain, as it was observed on the East Coast at the Ouinne Bay [15]. The winter season peak is often observed in satellite imagery and corresponds to a winter maximum in nutrients, linked to vertical mixing of waters during the cool season.
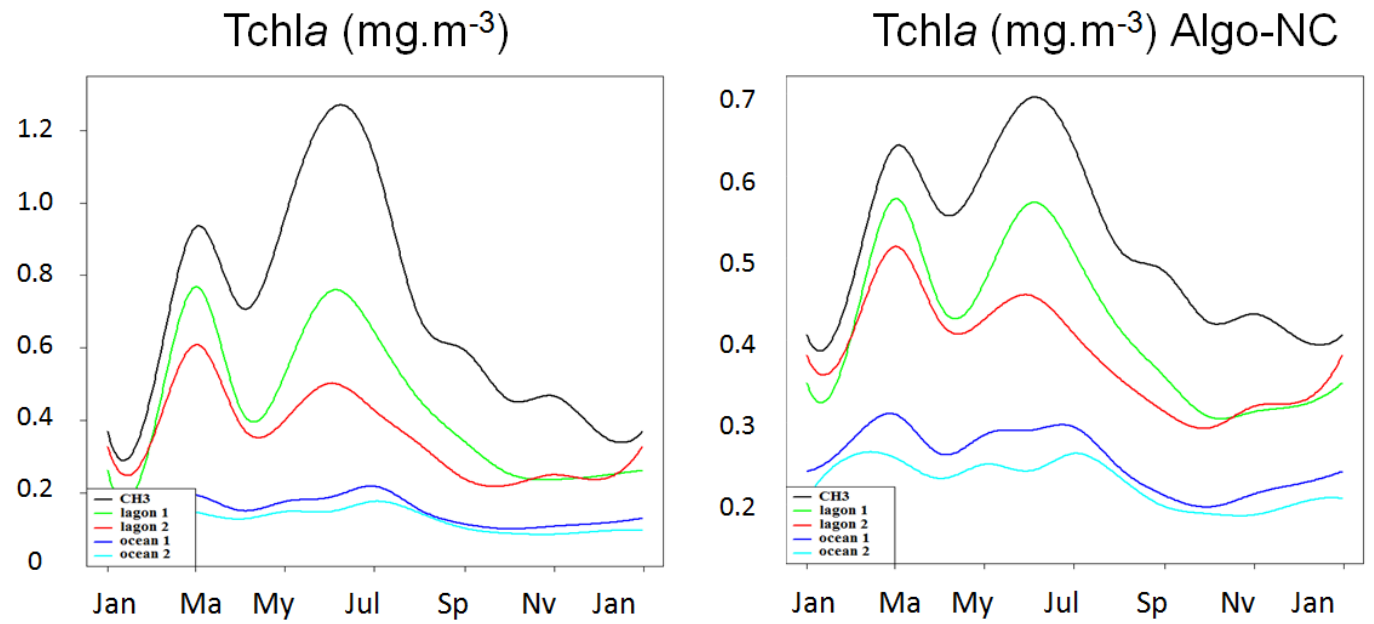

Figure 3. a) Concentration of chlorophyll a at five stations along a transect off the Thio mining village (Eastern Coast of New Caledonia, at three lagoon stations (CH3, lagoon 1 and lagoon 2) and two offshore stations (ocean 1 and ocean 2)); data where retrieved from satellite observations by a) the OC3 and b) the algoNC algorithm. by OC3 and b) by algoNC. Note the different scale for a) and b).

\section{Turbidity and CDOM (Eastern Coast of New Caledonia)}

For turbidity and $\mathrm{a}_{\mathrm{g}}(412)$ two peaks are observed for the three coastal studied stations: one in March and the other one in June-July. Offshore seasonal variations in turbidity were insignificant. The offshore variability of $\mathrm{a}_{\mathrm{g}} 412$ is similar to the one of Tchla inside the lagoon. 


\section{Turb (FTU) Ouillon et al. 2008}

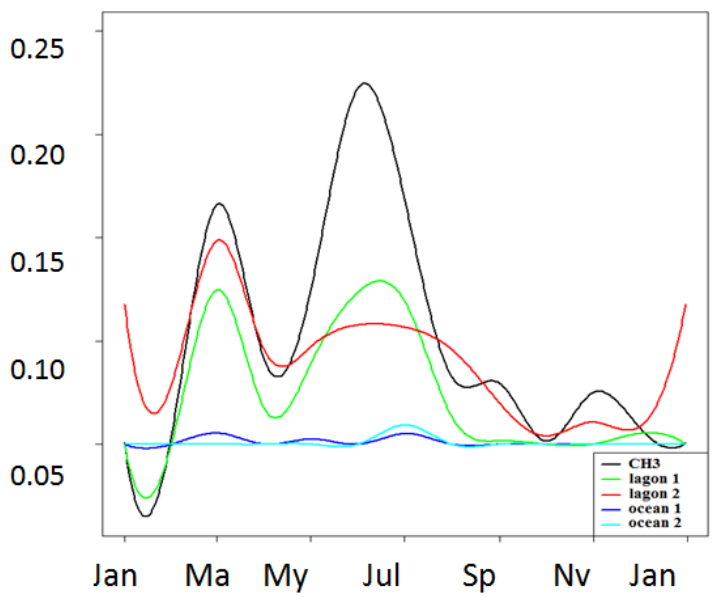

$\mathrm{a}_{\mathrm{CDOM}}(412)\left(\mathrm{m}^{-1}\right)$ Loisel

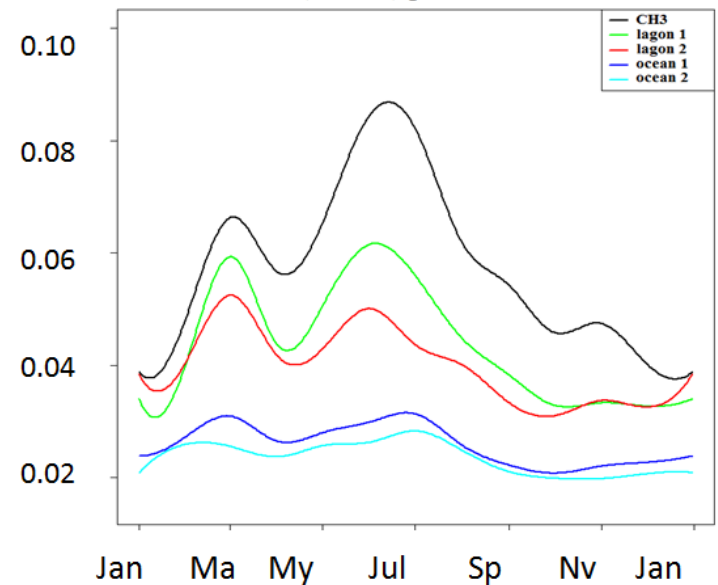

Figure 4. a) Turbidity b) $a_{g}$ (412) from MODIS along a transect off the Thio mining village (Eastern Coast of New Caledonia, at three lagoon stations (CH3, lagoon 1 and lagoon 2) and two offshore stations (ocean 1 and ocean 2)); data where retrieved from satellite observations.

For both parameters, we find a strong Coast - Ocean gradient with values of $3 \times 10^{-4}$ to $2.5 \times 10^{-3} \mathrm{~m}^{-1}$ signaling higher concentrations closer to the coast (Figure 3). The values are higher and more variable close to coast which is coherent with in situ observations. Striking here, variations are significantly higher for the two oceanic stations than for the other parameters observed.

\section{Backscattering coefficient}

The temporal mean annual series of $b_{\mathrm{bp}}$ are similar to parameters previously examined. The gradient between the coast and the ocean is also observed, with two peaks in March and June. The offshore seasonal variation in $b_{\mathrm{bp}} 550$ is significant.

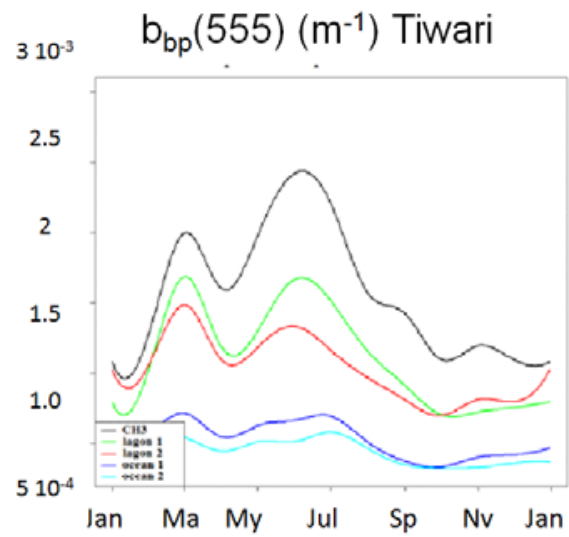

Figure 5. Particle backscattering at Thio $\left(b_{b p} 550\right)$ at five stations along a transect off the mining village of Thio (Eastern coast of New Caledonia).

Finally, all parameters show the same seasonal pattern over a year, and along the transect, except turbidity which is more constant offshore. 


\subsection{Seasonal and interannual meteorological conditions on the Eastern Coast}

Precipitations and temperature observed at Thio for the study period (2002-2010, MODIS archive) and until 2017 (including CALIOPE cruises) are shown in Figure 6a. Warm seasons are characterized by high precipitation with stronger events in January-February (warm cyclonic season) (Meteo France). The average annual cycle (average of all meteorological data for each month) is shown in Figure 6b. This indicates that a maximum in precipitation is in February while the minimum is in the winter months (June to October). During the period of our study with MODIS data and considered here (2002-2010), strong rain events were recorded centered at the summer months (03/2004, 03/2008 and 03/2009), and might have been responsible for increases of biogeochemical parameters values observed in March (the $1^{\text {st }}$ peak of the year-average cycle). For the more recent period covered by MODIS (2011-2017), not considered in this study (as MODIS data were not extracted and analyzed yet), there was an equivalent high rain event in December 2011 (Ex-Finna tropical storm), March 2013, March 2015 and March 2016. The December 2011 event (tropical storm Ex-Finna, Meteorologie Nationale) was documented by a MODIS image (see below Figure 7).

a)

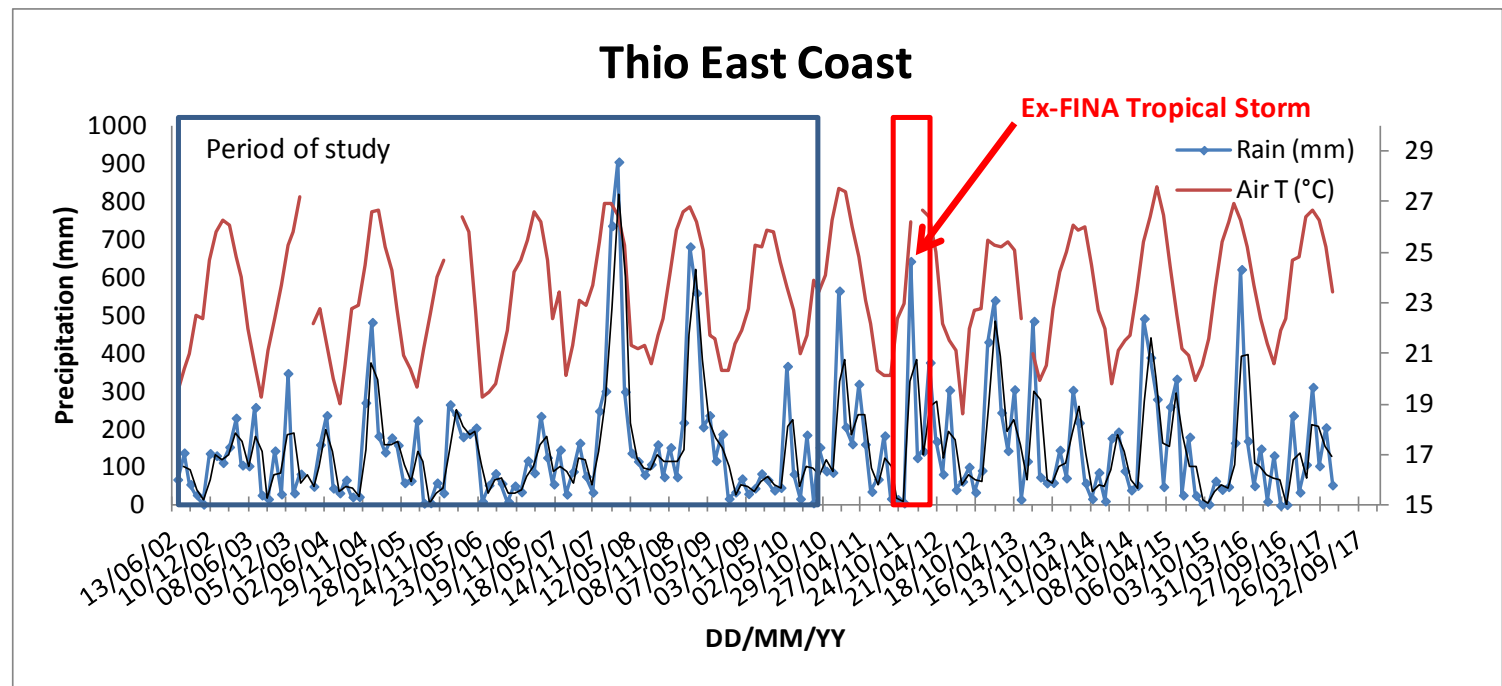

b)

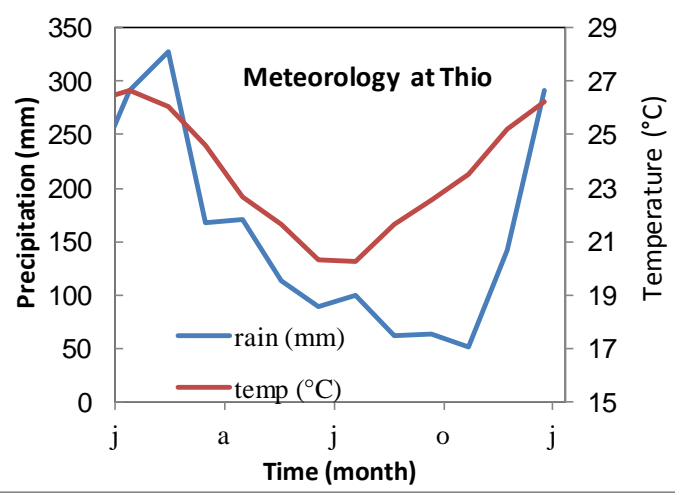

Figure 6. a) Meteorological parameters at the Thio station (precipitation and air temperature) on the Eastern Coast (Meteo France) from 1998 to 2017. The blue square corresponds to the period of our temporal study with MODIS b) Annual mean cycle at Thio during the MODIS for the study period. The date of the Ex-Finna tropical storm in December 2011 is indicated. 


\section{5- Response to the exceptional tropical storm (27 December 2011)}

Figure 7 shows the distribution of turbidity resulting from the application of [5] to MODIS Rrs for the 27 December 2011 tropical storm Ex-Finna. Recall that this algorithm performs well for waters $>20 \mathrm{~m}$.

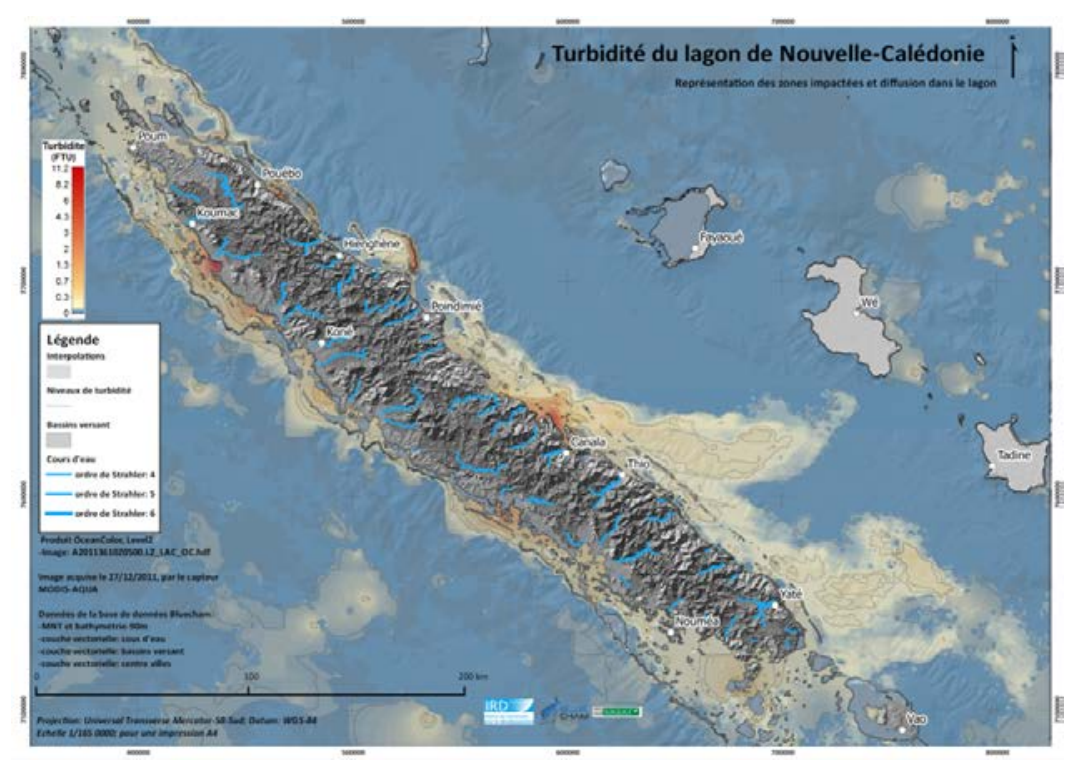

Figure 7. Map of turbidity as calculated from [5] from MODIS after the tropical storm Ex-Finna (December 2011). (Bluecham SAS.)

On this figure, MODIS turbidity values in coastal bays are high (they are overestimated by a factor of 20 due to bottom effect [7]). Such overestimated high values are observed on shallow bays such as North of the Bay of Canala on the East coast, or in the Bay South of Koumac on the Northern coral coast which are particularly shallow (< 10 meters) Apart from these enclosed shallow bays, as the lagoon is deeper than 10 meters, turbidity distribution does not present any overestimation and corresponds well to in situ measurements. Striking features observed on the MODIS imagery are the two large plumes of about 0.2 FTU turbidity, and of a size of $20 \mathrm{~km}$ by 60 kilometers extending offshore and far beyond the barrier reef, up to the middle of the Loyalty Channel to the Lifou Island. Two " turbidity centers" can be identified after this rain episode, one situated in front of the large mining extraction sites along the Eastern Coast (Canala), and a one extending at the southern tip of the East Coast to the Mare Island. This plume is connected to several mining extraction centers ("Côte Oubliée" from villages of Yaté to Thio) and possibly influenced by the Yaté river outflow. Plumes are deviated to the South and East due to the entrainment of water by winds and currents forming large gyres taken by the southern coastal Vauban current flowing along the East Coast [10]. The entrainment of particles out of the lagoon may enrich waters around New Caledonia and is the typical "Island mass effect" after strong rain.

\section{DISCUSSION AND CONCLUSION}

From the five stations corresponding to the in situ coast to ocean transects, the biogeochemical parameters were estimated from MODIS reflectance and analyzed by constructing an average annual cycle issued from the archive of satellite data MODIS-Aqua from 2002 to 2010. All time series (Chla, turbidity, $\mathrm{a}_{\mathrm{g}}(412)$ 
backscattering at $550 \mathrm{~nm}$ ) indicated values typical of oligotrophic waters in tropical lagoons subject to rain inputs [16]. They present two peaks in March and June, the June peak displaying twice the amplitude of the March peak. The March peak is attributed to outputs from land linked to rain. The July one is typical of the dry season. A strong gradient coast - ocean is found for all parameters, with a strong opposition between coastal stations and open ocean ones. This annual mean series 2002-2010 off the Thio mining village might have included some episodic events appearing in the rainy season (most of them in January of February) though these events were weaker during the 2002-2010 period. Nevertheless, if the March peak corresponds to a warm season high rain impact, the second peak in June, which is higher for all parameters, cannot be related to rain. This secondary peak might be related to the winter vertical mixing affecting both open ocean and lagoon waters. The strongest spatial extension of turbidity and other parameters happens after tropical storms and affects probably all parameters, particles and CDOM. Phytoplankton and associated detritus, if not dominated by toxic filamentous cyanobacteria, can also feed coral reefs. Finally, the export of fine particles associated with colloids and/or CDOM can also contribute to the dispersion of trace metals to the barrier reefs of the East Coast and offshore. The issue of the positive or negative effect of this possible input of trace metals toward the coral reefs is still open.

\section{ACKNOWLEDGMENTS}

We thank the INSU EC2CO TREMOLO (Transfert de Matière Organique dissoute coLOrée entre terre et lagon de la Nouvelle-Calédonie) project, all participants at the Centre IRD of Noumea (New Caledonia). We thank Philippe Gérard (MIO/LAMA) for chemistry analyses, and David Varillon for his great help on board (IMAGO, IRD). We also thank captains and crews of R/V Alis. The National Aeronautics and Space Administration supported Robert Frouin under various grants. We thank CNRT «Centre de Recherche Technologique sur le Nickel et son Environnement » for funding Guillaume Wattelez (Contract DYNAMINE, DYNamique des métaux de la MINE au lagon).

\section{REFERENCES}

[1] Dupouy, Cécile, Neveux, J., Ouillon, S., Frouin, R., Murakami, H., Hochard, S., and Dirberg, G.,’Inherent optical properties and satellite retrieval of chlorophyll concentration in the lagoon and open ocean waters of New Caledonia,” Marine Pollution Bulletin 61, 503-518 (2010).

[2] Murakami, H. and Dupouy C., Atmospheric correction and inherent optical property estimation in the southwest New Caledonia lagoon using AVNIR-2 high-resolution data,” Applied Optics 52 2, 182-198 (2013).

[3] Minghelli-Roman A., and C. Dupouy, "Influence of water column chlorophyll concentration on bathymetric estimations in the lagoon of New Caledonia, using several MERIS images,” IEEE Journal of Selected Topics in Applied Earth Observations and Remote Sensing 6, 739-745 (2013)

[4] Wattelez, G., Dupouy, C., Mangeas, M., Lefèvre, J., Touraivane, Frouin, R., A statistical algorithm for estimating chlorophyll concentration in the New Caledonian lagoon, Remote Sens. 8(1), 45; doi:10.3390/rs8010045 (open access) (2016).

[5] Ouillon, S., Douillet, P., Petrenko, A., Neveux, J., Dupouy, C., Froidefond, J.M., Andrefouët, S., and Muñoz- Caravaca, A., "Optical algorithms at satellite wavelengths for total suspended matter in tropical coastal waters,” Sensors 8, 4165-4185 (2008). 
[6] Nechad, B.; Ruddick, K.G. and Park, Y. "Calibration and validation of a generic multisensor algorithm for mapping of total suspended matter in turbid waters”. Remote Sensing of Environment 114, 854 - 866 ( 2010)

[7] Wattelez, G., Dupouy, C., Juillot, F., Fernandez, J.M., Lefèvre, J., Ouillon, S., "Remotely-sensed assessment of turbidity with MODIS in the oligotrophic lagoon of Voh-Koné-Pouembout area, New Caledonia”, Water, 9, 737, http://dx.doi.org/10.3390/w9100737 (2017).

[8] Favareto, L., De Moraes Rudorff, N., Kampel M., Frouin, R., Röttgers, R., Doxaran, D., Murakami H., and Dupouy C., "Bio-optical properties of the Eastern lagoon of New Caledonia, South Tropical Pacific", Remote Sens., 10(7), 1043; https://doi.org/10.3390/rs10071043 (2018)

[9] Tiwari, S. P., and Shanmugan, P., "An optical model for deriving the spectral particulate backscattering coefficients in oceanic water”. Ocean Sci., 9, 987-1001, doi:10.5194/os-9-987-2013 (2013)

[10] Martias, C., Tedetti M., Lantoine, F., Jamet L., Dupouy, C., "Spatial distribution of chromophoric dissolved organic matter and trace metals in the New Caledonia tropical lagoon (South Pacific Ocean)", Science of the Total Environment, 616-617, 438-452, doi: 10.1016/j.scitotenv.2017.10.261 (2018).

[11] Loisel, H., Vantrepotte, V., Dessailly, D., and X. Mériaux, “Assessment of the colored dissolved organic matter in coastal waters from ocean color remote sensing”, Optics Express, DOI:10.1364/OE.22.013109 ( 2014)

[12] Dupouy, C., Frouin, R., Röttgers, R., Neveux, J., Gallois, F., Panché, J.-Y., and Gerard, P., “Ocean color response to an episode of heavy rainfall in the lagoon of New Caledonia," Proc SPIE 7459, 74590G-74590G10 (2009).

[13] Röttgers, R., and Doerffer, R., "Measurements of optical absorption by chromophoric dissolved organic matter using a point-source integrating-cavity absorption meter," Limnology and Oceanography Methods 5, 126-135 (2007).

[14] Lefèvre, MODIS-DB around New Caledonia and Fiji. Report. 30 p (2010).

[15] Dupouy, C., Röttgers, R., Tedetti, M., Martias, C., Murakami, H., Doxaran, D., Lantoine, F., Rodier, M., Favareto, L., Kampel, M., Goutx, M., Frouin, R., "Influence of CDOM and Particle Composition on Ocean Color of the Eastern New Caledonia Lagoon during the CALIOPE Cruises”, Proc. of SPIE Vol. 9261, 92610M • (C) 2014 SPIE (2014)

[16] Blondeau-Patissier, D., Brando, V., Oubelkheir, K., Dekker, A., Clementson, L., and Daniel, P., "Biooptical variability of the absorption and scattering properties of the Queensland inshore and reef waters, Australia,” Journal of Geophysical Research 114 (C5), (2009). 